\title{
GENTE REBELDE Y PUEBLOS TUMULTUOSOS: LOS SANTANDERES Y SUS PRIMERAS JUNTAS POR LA INDEPENDENCIA 1810-1813'
}

Óscar Mauricio Pabón Serrano2

Universidad Santo Tomás - Bucaramanga

\section{Resumen}

El presente texto, producto de investigación histórica, tiene como objetivo central interpretar los acontecimientos que dieron inicio al proceso de Independencia en las principales poblaciones de las Provincias ubicadas en el nororiente del Virreinato de la Nueva Granada. Tomada como referencia histórica la crisis política desatada por el secuestro de la Monarquía Española en 1808 por parte de las fuerzas bonapartistas, se estudió la formación de las Juntas de Gobierno Locales, dado que estos cuerpos políticos concretaron el comienzo de la revolución de Independencia y la reasunción de la soberanía.

\section{Palabras clave:}

Nueva granada, provincias, crisis monárquica, independencia, juntas de gobierno, soberanía y primera república.

\section{REBELIOUS PEOPLE AND FIGHTING TOWNS: SANTANDERES AND THEIR FIRST GOUNGILS TO BE INDEPENDENT 1810-1813}

\section{Albstract}

The text is a history investigation product that has as main aim, to interpret the events that caused the starting of Independence process took place in main towns belonging to Provinces located in the North-east of Nueva Granada. Taking into account the political crisis as historical reference because of the Spaniard Monarchy sequestration in 1808 by Bonapartists forces; creation of government local councils, because these political bodies came true the independence revolution starting and sovereignty resumption.

\section{Key words:}

Nueva Granada, provinces, monarchy crisis, independence, government councils, sovereignty, first republic.

\footnotetext{
1 El presente artículo contiene parte de los resultados de investigación del trabajo realizado para optar al título de Magíster en Historia. El proyecto se enmarca dentro de las actividades académicas desarrolladas por la línea de Historia Política de la Maestría de Historia de la Escuela de Historia de la Universidad Industrial de Santander, la cual se encuentra, en cada una de las últimas cohortes, jalonada por el "Grupo de Investigaciones Históricas sobre el Estado-Nacional Colombiano", dirigido por el Doctor Armando Martínez Garnica, registrado en COLCIENCIAS en categoría B.

2 Egresado de la Escuela de Historia de la Universidad Industrial de Santander, Magíster en Historia de la misma Institución e investigador de la Historia Política y Militar del siglo XIX. Profesor del Departamento de Humanidades de la Universidad Santo Tomás y asesor de calidad en Educación Superior de las Unidades Tecnológicas de Santander; en el 2010 fue unos de los ganadores de la convocatoria Becas Bicentenario en el área de literatura, modalidad ensayo histórico; y en el 2009 ganó el Concurso Nacional de Ensayo Histórico "Historias Locales", convocado por la Alta Consejería Presidencial para el Bicentenario de la Independencia. promauricioserrano@hotmail.com
} 
METODOLOGÍA Y FORMAS DE PROCESAR LA INFORMACIÓN

La metodología de los estudios históricos supone inicialmente el discernimiento de un problema de investigación, es decir, la construcción e interpretación de un tramo del pasado acontecido a una comunidad de individuos y el registro escrito de la construcción planteada. El problema de investigación intenta cuestionar los juicios sobre lo acontecido o presentar la historia de un acontecimiento no rememorado. Ahora bien, el carácter científico de la representación histórica lo da el método, que estriba en el manejo crítico de las fuentes primarias, en la complementación o construcción de los hechos y la adaptación de un soporte conceptual. En consecuencia, un mismo suceso o evento puede ser histórico o no, cuestión que depende de la forma como se da a conocer. Por esta razón el carácter histórico no radica en los eventos por sí mismos, sino invariablemente en la forma como llegamos a conocerlos.

La investigación histórica y su escritura condensa un esfuerzo realizado con el propósito de establecer hechos, sucesos o eventos en un ámbito y contexto que interesa al historiador. Aquí la metodología es el modo en que se estructuran u orientan los problemas y se escrutan las respuestas. El historiador efectúa un esfuerzo sistemático que inicia con la delimitación de un problema de investigación, con la proposición de preguntas y viabilidades, las cuales se verifican a partir del análisis de la información primaria a fin de formular un cuerpo de argumentaciones y conclusiones consistentes. La historiografía busca llenar en parte la brecha que se abrió cuando el presente rompió con el pasado y surgió como una construcción del pasado lograda únicamente por medio de la escritura. La escritura es el testimonio de la búsqueda del sentido de la experiencia en la vida y busca recuperar aquel sentido regresan- do al pasado, asumiendo así la historia un acto reflexivo respecto al presente.

La fuente de información es el medio que dispone $u$ ofrece datos relevantes sobre el asunto investigado, datos o información que se muestran directa o indirectamente. Las fuentes al igual que los hechos también se construyen. La fuente primaria está directamente relacionada en términos de tiempo y espacio con el evento o suceso que interesa al historiador, una vez identificadas -habilidad heurística- y clasificadas se determina la calidad y relevancia de la información que la fuente suministró. La información debe estar sujeta a un análisis cuidadoso, mediante el proceso de crítica o juicio de la fuente el historiador determina las evidencias históricas sobre las cuales se apoya para interpretar o comprobar sus planteamientos. Esta es la llamada habilidad hermenéutica. De hecho, el procesamiento de la información se funda en el método historiográfico nombrado como la crítica de fuentes, este procedimiento otorga las referencias de la construcción histórica y la distingue en parte de la ficción literaria.

La escritura es el instrumento que ayuda al historiador a plasmar materialmente los juicios de su problema de investigación, es el medio de presentación de lo acontecido. Las propiedades específicas de la narración histórica tienden a la organización "foliada" de un discurso que se agarra a los materiales con los que cuenta para producir una comprensión, las propiedades tienden a fortalecer los procesos de acreditación específicos bajo los cuales la historia garantiza su régimen de verdad (citas, notas, gráficos, estadísticas y demás etc.). Michel de Certeau subrayó que la escritura histórica es un relato que construye su discurso según los procesos de "narrativización" para ordenar los procesos del problema de investigación. La narración histórica se acerca más a la construcción que a la representación fidedigna. La narración histórica conserva 
una coherencia narrativa y una conformidad con los documentos, estos procesos complementan la construcción de los "hechos" y son los fundamentos técnicos de la disciplina (elección de fuentes, construcción del discurso, hipótesis, crítica, verificación, conceptualización).

\section{INTRODUCCIÓN}

Antes de los acontecimientos del 20 de julio de 1810 en la capital del Virreinato de Nueva Granada, los cuales sirvieron como referente para la conmemoración nacional del día de la Independencia del actual Estado colombiano, algunas provincias y pueblos de este reino americano de la Corona española iniciaron entre el miedo y la incertidumbre un proceso que en aquel contexto del absolutismo político establecido en tres siglos de dominación, representó una acción revolucionaria a la vez que ilegítima. Por esta razón, en las conmemoraciones locales del Bicentenario se anunció en amplios carteles publicitarios frases como: En la Independencia iEI Socorro es primero!, o En la Independencia iSantander es primero! Si bien, el presente artículo no tiene este propósito reivindicativo, ni menos aún hacer una historia de bronce o monumental sobre los primeros días de la Independencia en la región que hoy conocemos como los santanderes, si intenta descentralizar la mirada del proceso independentista iniciado en algunas provincias de la periferia neogranadina y consumado en la ciudad de Santafé.

El siguiente artículo resume los resultados de investigación en la parte que se refiere a la experiencia juntera de cuatro localidades de la región, contenidos en la investigación histórica titulada "El proceso de Independencia en la antigua Provincia de Pamplona 1810-1816", realizada por el historiador Óscar Mauricio Pabón Serrano como proyecto de grado para optar al título de Magíster en Historia de la Universidad Industrial de Santander. En líneas generales este proyecto se centró en el estudio de los aspectos relacionados con el papel de las élites y las familias principales en la reasunción de la soberanía, las experiencias junteras locales, el debate sobre las soberanías provinciales, la función legitimadora del movimiento constitucional y las batallas regionales por la Independencia en los tiempos de la Primera República neogranadina. La estructura del artículo contiene primero una contextualización histórica de las Independencias hispanoamericanas en el marco de la crisis de la Monarquía española; segundo, un relato sobre la formación de las Juntas de Gobierno de las poblaciones de El Socorro, Pamplona, San Juan de Girón y Ocaña; y tercero, las consideraciones finales sobre los tópicos abordados.

\section{Los pueblos hispanoamericanos y la reasunción de la soberanía}

La formación de Juntas de Gobierno en algunas localidades de los reinos hispanoamericanos fue sólo posible en el marco de la inesperada crisis de la Corona española. Este evento hace referencia al secuestro y abdicación de los Reyes de España en 1808 por parte del régimen bonapartista, acontecimiento que dejó acéfalo al Estado Monárquico y eliminó el referente de la soberanía. Tras el golpe de los franceses los peninsulares formaron la Junta Suprema Central y Gubernativa del Reino y ésta fue el cuerpo que asumió los poderes centrales durante los primeros meses de la ocupación napoleónica. Con la publicación del decreto del 22 de enero de 1809 por parte de la Junta Central, los territorios americanos se concibieron como "parte integrante y esencial" de la Monarquía española, empezó así el proceso que definió la nación hispánica como "Ia totalidad de los españoles de ambos hemisferios". El proyecto de la nación española trajo implícito el principio de igualdad de los pueblos, en adelante los reinos hispanoamericanos 
no serían colonias sino parte integrante de la nación e iguales en derechos.

La idea de nación moderna surgida en el contexto de las revoluciones atlánticas implicó un proyecto de igualación política de los individuos reunidos en una comunidad de ciudadanos cuyo vínculo sería exclusivamente político. La igualdad se planteó como el principio de la acción política en la modernidad, el único vínculo entre los individuos del nuevo régimen social -la nación- sería la igualdad política. De esta manera, en la igualdad de representación confluyeron tanto la esencia de la revolución como el principio moderno de la acción política (Quijada, 2003: p. 294) ${ }^{3}$. Cumplidos dos años de la crisis monárquica, el tema de la igualdad representó el debate central que llevó a la ruptura de algunos reinos de ultramar con los poderes que en la península reemplazaron la Corona. Los discursos e ideas sobre la nación permearon en este interregno la mentalidad de las élites ilustradas en Hispanoamérica, pero la prometida igualdad entre los españoles de ambos hemisferios fue desconocida por los poderes centrales y fueron dos los aspectos que causaron el malestar que llevó a los americanos a conformar sus propias Juntas de Gobierno: su desigual representación en los poderes centrales y el impedimento para levantar Juntas en América.

Las noticias de la autodisolución de la Suprema Junta Central y formación del Consejo de Regencia que en enero de 1810 asumió la autoridad soberana, Ile-

\footnotetext{
3 Como lo señaló Mónica Quijada, el concepto de integración en una nación única manifestó el profundo rechazo a la condición de colonias expresado por los diputados americanos en las Cortes de Cádiz. La negación del status “colonial a cambio de la igualdad de derechos fue fundamental para la autoidentificación de los americanos en el cuerpo de la nación. La negación de esta condición fundamentó la pertenencia a la nación española, cuyos dos pueblos, el peninsular y el americano, debían ser iguales en derechos. "La perfecta igualdad entre provincias europeas y americanas es lo que justifica la pertenencia de estas últimas a la nación española". De esta manera, vinculados al concepto de nación única e igualitaria, "aparecen los dos grandes temas de la Independencia [y la revolución política]: la representación y la
} soberanía". varon a varias ciudades de la Capitanía General de Venezuela y los Virreinatos de Nueva Granada y Río de la Plata a formar sus propias Juntas de Gobierno. Parte de Suramérica negó el reconocimiento de la Regencia, al señalar su poder como precario e ilegítimo, de esta manera la formación de Juntas americanas apresuró la desintegración territorial de la Monarquía española al tiempo que inició la formación de los primeros Estados independientes hispanoamericanos. François-Xavier Guerra señaló que el origen de estos Estados no evoca procesos internos o planeados en este lado del Atlántico y señala que el comienzo de las historias nacionales lo marcó la crisis revolucionaria en la península ibérica, crisis inesperada e inédita que desató la desintegración de la Monarquía española y el desarrollo de profundos cambios ideológicos.

La interpretación de las Independencias hispanoamericanas en un contexto de crisis indica que antes de 1808-1810 es imposible hablar de naciones y nacionalismos en la América española, las naciones se piensan y se constituyen tras el colapso de la Monarquía por el golpe de los franceses. En este sentido, la Independencia implicó básicamente la reasunción de la soberanía y la revolución política fundada en el régimen representativo. Sobre este proceso y la crisis monárquica Jaime Rodríguez sostiene que en el mundo atlántico, la revolución hispánica presume un caso paradigmático que confluyó con la formación de una decena de repúblicas surgidas en el contexto del colapso imperial. Rodríguez señala enfáticamente que:

“la Independencia de la América española no constituyó un movimiento anticolonial, como muchos aseguran, sino que formó parte no sólo de la revolución dentro del mundo hispánico, sino que también de la disolución de la Monarquía española (...). El colapso de la Monarquía española, como 
resultado de la invasión francesa de la Península y la abdicación de sus gobernantes inició una serie de eventos que culminaron con el establecimiento de un gobierno representativo en todo el mundo español (...)." (Rodríguez, 2004: pp. 15-37).

La Independencia condujo hacia la transición de regímenes, es decir, a una cambio en la manera como los hispanoamericanos serían mandados y gobernados. La reasunción súbita de la soberanía por parte del pueblo significó el paso de la política antigua a la política moderna. Las nuevas nociones de igualdad política, ciudadanía, soberanía nacional y gobierno representativo se aplicaron bruscamente y marcharon en contra de la política antigua. La transición hacia la política moderna basada en un Estado-Nación de ciudadanos -libres e iguales- se construyó a partir de la referencia francesa, modelo que resultó ajeno a la tradición hispánica. Así se optó por el camino de la nación en contra de las tradiciones seculares y la política corporativa, la tradición política obstaculizó la construcción -modernade la nación. La experiencia política de la modernidad fue incompatible con la política grupal-estamental, el nuevo sistema generó enormes malestares en una sociedad todavía acompasada por las permanencias políticas coloniales (Guerra, 1998: pp. 109-139).

En definitiva, la crisis desatada por el secuestro de la Monarquía española y los cambios ideológicos jalonados por el debate sobre la nación, motivaron a algunas localidades de la América española a reasumir la soberanía y depositarla en las Juntas de Gobierno que constituyeron para aquel propósito. Tomado como referencia este contexto histórico, el presente trabajo interpretó los acontecimientos que rodearon la formación de las Juntas locales en el oriente de la Nueva Granada, región que actualmente conocemos como los santanderes.

\section{Historia regional de los primeros días de la experiencia juntera}

La formación de Juntas locales o provinciales de gobierno representa en el imaginario colectivo de los colombianos las jornadas en las que los vasallos neogranadinos declararon su Independencia respecto al dominio español. El estudio de este capítulo de la historia regional santandereana permitió redimensionar dos aspectos en cuanto a las experiencias locales que optaron por la reasunción de la soberanía: primero, la naturaleza espuria, tumultuosa e ilegal que rodeó la formación de las Juntas, reflejada en la destitución violenta de las autoridades peninsulares y en los motines que como en las localidades de Pamplona y El Socorro precedieron la toma del poder político; y segundo, el liderazgo de las "élites ilustradas" locales para concretar un proceso que puede llamarse revolucionario. Muchos de los miembros de estas élites, siendo "de origen noble", descendientes de españoles europeos fundadores de las poblaciones indianas o de otros recién llegados, siendo criollos principales y fieles empleados de la Corona, fueron los que asumieron con mayor vehemencia el liderazgo político y militar de una lucha peligrosa desde todo punto de vista.

El estudio de las experiencias locales en los primeros días de la Independencia dio por hecho que las Juntas americanas fundamentaron sus acciones en los mismos principios jurídicos invocados por los peninsulares: ido el Rey, la soberanía recae en el pueblo. En el caso del Virreinato de la Nueva Granada, la crisis monárquica y las noticias de la formación del Consejo de Regencia, exacerbaron las tensiones de hecho ya existentes entre peninsulares y criollos, en la capital virreinal y en las provincias los ayuntamientos controlados por criollos se enfrentaron a los gobernadores europeos por desconfianzas de 
toda índole. Las últimas noticias que de España trajeron los Comisionados Regios a la Nueva Granada conmocionaron más el ambiente político. Así las cosas, en los primeros días de julio de 1810 algunas ciudades principales formaron sus propias Juntas, juraron fidelidad a Fernando VII y se refirieron a la legitimidad de la Regencia siguiendo ciertas recomendaciones del Comisionado Antonio de Villavicencio. El movimiento empezó en Cali, Pamplona, El Socorro y se concretó el 20 de julio en Santafé; varias Juntas se resistieron al intento de dominación y unificación emprendido por Santafé, se declararon autónomas y otras aceptaron la autoridad de la Regencia (Rodríguez, 1998: pp. 182-186).

\section{La Junta de la Villa de Nuestra Señora del Socorro ${ }^{4}$}

Durante el gobierno virreinal de José de Ezpeleta la Villa de El Socorro cristalizó su aspiración de obtener mayor autonomía en el orden jurisdiccional de la Nueva Granada. Aquella vieja demanda contenida en la capitulación comunera de 1781 se concretó con la reforma que dividió en tres partes el extenso y antiguo Corregimiento de Tunja, desde 1795 y por decreto real Pamplona y El Socorro se establecieron como Provincias con jurisdicción sobre los pueblos subalternos que congregaron. De la Provincia de EI Socorro hizo parte el Cabildo de su villa, el de la villa de San Gil, el de la ciudad de Vélez, además de 19 parroquias y 8 pueblos de indios. Al tiempo que el régimen monárquico colapsaba en la metrópoli española por causa de la invasión francesa, en 1808 y 1809 los Corregidores peninsulares de las recién formadas Provincias se posesionaron en sus empleos.

4 El texto del historiador Horacio Rodríguez Plata titulado "La antigua provincia del Socorro y la Independencia", es hasta la fecha la más importante referencia e investigación sobre la experiencia independentista de esta Provincia neogranadina. Con motivo de la conmemoración del Bicentenario la obra de Rodríguez fue reeditada por la empresa Sistemas y Computadores, son estas las razones por la que se recomienda su lectura en el sitio Web de la Fundación El Libro Total.
Sin ninguna experiencia en los asuntos indianos, el abogado asturiano José de Valdés y Posada se hizo cargo en marzo de 1809 del gobierno del El Socorro y de esta manera la pretendida autonomía de sus gentes quedó condicionada.

Los acontecimientos de Quito y Caracas, más las noticias que venían de Europa colocaron en Estado de máxima alerta a los Corregidores de Maracaibo, Tunja, Pamplona, El Socorro y al Virrey Antonio Amar, quienes condenaron el retraimiento de la justa obediencia a la autoridad suprema y las intenciones de formar Juntas locales de Gobierno. La situación de incertidumbre y desconfianza en la villa de Nuestra Señora del Socorro se agudizó por la pugna que surgió entre el Corregidor Valdés y los miembros del Cabildo, pues en junio de 1810 este cuerpo desconoció la autoridad del Consejo de Regencia la cual fue invocada por el Virrey en Santafé. Los socorranos alegaron que legalmente estaban impedidos para reconocer la Regencia porque primero debían conocer la opinión de los cuerpos de la capital del reino, y segundo porque no contaban con el voto de los pueblos de su jurisdicción para propalar tal reconocimiento. El atrevimiento de los capitulares de EI Socorro rebosó más los ánimos cuando propusieron directamente al Virrey celebrar cabildos abiertos en la localidades de la Provincia para deliberar sobre el reconocimiento y obediencia que debía prestarse al nuevo Consejo de Regencia.

El fiscal de la Real Audiencia excusó "la convocación de cabildo abierto" y solicitó a los cabildos y pueblos de la Provincia obedecer al Consejo de Regencia, recordándoles que desde el 2 de junio de 1810 las autoridades de Santafé lo habían hecho y ordenado. El Corregidor Valdés quedó obligado a compeler a los alcaldes ordinarios de la villa del Socorro para que prestasen 
dicho juramento de obediencia. Sin embargo, los capitulares mantuvieron su postura y por esta razón se les abrió una causa por desacato. Por comentarios propalados por hombres fieles al Corregidor, se extendió el rumor que los primeros traidores destinados al cuchiIlo serían el Alcalde de primera vara y el administrador de aguardientes, quienes suplicaron por sus seguridad ante el mismo José Valdés. Pero la respuesta del Corregidor confirmó las sospechas sobre el apresamiento que preparaba con la tropa puesta a su disposición por el Virrey, comandada por dos peninsulares, el Teniente Antonio Fominaya y el alférez Ruiz Monroy. El pleito entre el Corregidor y los Alcaldes se agudizó por la causa sumaria que contra él abrieron por sus planes de ejecutar una lista de proscritos, los Alcaldes convocaron el auxilio de las gentes de todas las parroquias de la Provincia, mientras que José Valdés acuarteló las tropas venidas de Santafé (Martínez, 2010: pp. 16-31).

Las tensiones entre el Corregidor peninsular y los socorranos se hicieron insostenibles la noche del nueve de julio de 1810, cuando la tropa del Alférez Monroy amenazó con hacer fuego sobre tres parroquianos que caminaban por el cuartel. Tras estas voces concurrió el pueblo sobre el cual llovieron balas desde los balcones del cuartel, el desigual enfrentamiento dejó ocho pobladores muertos y sólo la mediación de los jueces evitó que la masacre hubiese sido más numerosa dada la superioridad de las fuerzas fieles a la Regencia. EI pueblo aguardó en la plaza de la villa y allí pasó la noche, al amanecer del día diez la tropa se retiró y atrincheró en el Convento de los Capuchinos, las partes en disputa izaron las banderas de guerra y los hombres del pueblo pusieron sitio al convento. En las primeras horas del combate la tropa tuvo el control porque su posición le permitió tener a tiro de fusil a los furiosos amotinados, tras la muerte de otros hombres bajo fuego de la tropa fiel al Corregidor, el pueblo clamó que no quedase piedra sobre piedra y que se pasase a cuchillo a cuantos se hallasen dentro. Más de ocho mil hombres que arribaron de los pueblos vecinos sitiaron el Convento y se prepararon para reducir a sangre y fuego a la tropa allí acantonada, nuevamente la intervención de los jueces motivó la rendición y entrega de armas de la tropa. El corregidor Valdés, el Teniente Fominaya y el Alférez Monroy quedaron presos en la Administración Principal de Aguardiente, donde recibieron buen trato.

Una vez el pueblo tumultuoso consumó la deposición contra la superior autoridad de la Provincia, el Cabildo declaró que había reasumido el gobierno de la jurisdicción, agregando seis principales de la villa para ayudar en este menester. Esta Junta de Gobierno animó a los cabildos de la villa de San Gil y de la ciudad de Vélez para que enviasen sus representantes. En resumen, la formación de la Junta del Socorro sucedió en un ambiente exacerbado, allí los pobladores decidieron amotinarse contra su Corregidor y optar por el autogobierno temiendo las represalias del Virrey Amar. Los amotinados alegaron haber "sufrido por espacio de un año al corregidor don José Valdés Posada, que con una actividad y celo sin igual ha querido sostener entre nosotros las máximas de terror y espanto". Restituido el pueblo del Socorro, depositó "provisionalmente el gobierno en el muy ilustre Cabildo, para que ayuden al desempeño de la multitud de asuntos en que debe ocuparse para defender la patria de las medidas hostiles que tomará el señor virrey de Santafé contra nosotros". El acta de formación de la Junta de la Villa del Socorro, firmada el 11 de julio de 1810, no hizo referencia a favor o en contra de la Regencia, declaró únicamente que "habiéndose restituido 
la confianza pública; ya sabemos que podemos conservar nuestra sagrada religión y esta provincia a su legítimo Soberano, el señor don Fernando VII (...)" (Martínez \& Quintero, 2008: pp. 299-303)

\section{La Junta Suprema Provincial de Pamplona}

Pamplona recibió el título de Ciudad el 3 de agosto de 1555 y desde 1795 se estableció como capital del nuevo Corregimiento que tuvo el mismo nombre e integró las poblaciones de Salazar de las Palmas, Girón, Cúcuta y la Villa del Rosario ${ }^{5}$. La fragmentación en tres partes del antiguo Corregimiento de Tunja se hizo para ejercer un control directo sobre los territorios del Reino, el encargado de promover esta reforma fue el Regente Visitador Gutiérrez de Piñeres en 17781780. Diez años después de erigirse la Provincia de Pamplona, en enero de 1805, fue designado como primer Corregidor el granadino Joaquín Camacho. Hallándose vacante el empleo el Virrey Amar convino proveerlo a este abogado de la Real Audiencia, "para que lo (sirviera) por cinco años más o menos, a arbitro de este Superior Gobierno" (Gaceta Histórica, 1953: p. 141-142).

En 1808 llegó de España Juan Bastús y Faya, nombrado por el Rey en 1807 Corregidor Justicia Mayor de la Provincia de Pamplona, a quien el Virrey decidió darle posesión ante la abdicación de Bayona (Gaceta Histórica, 1953: p.142). Al contrario del Corregidor Camacho, Bastús mantuvo pésimas relaciones con los habitantes de la ciudad, su despotismo y arrogancia granjearon el odio de las familias principales, que además vieron frustradas sus esperanzas de colocar uno de sus representantes en el gobierno

\footnotetext{
5 Además de la ciudad de San Juan de Girón, el Corregimiento de Pamplona incluyó los territorios de la Parroquia del Pie de la Cuesta, de la Parroquia de Chiquinquirá y San Laureano del Real de Minas de Bucaramanga, el sitio de Los Santos y otras poblaciones que actualmente hacen parte del Departamento de Santander.
}

provincial. Esta situación se agravó a medida que las noticias llegaban de Europa, ante las amenazas y la conmoción por lo ocurrido desde los sucesos de Bayona el Corregidor Bastús endureció su postura y trato.

La actitud desafiante y grosera del Corregidor Bastús contribuyó a planear su destitución, constituir la Junta de Pamplona y formar la primera milicia para defensa de la causa, acontecimientos impensables si no hubiesen ocurrido los sucesos de Bayona, la formación de la Regencia y los movimientos de Quito, Caracas y Cartagena. Historiadores y académicos han discutido sobre la veracidad de lo ocurrido en Pamplona desde finales de junio de 1810, pero a partir de los escasos testimonios sobre lo acontecido se pueden confirmar varios puntos

Fue durante la celebración del día de San Pedro, patrono de la ciudad y devoción central de la Santa Hermandad, que el pleito entre el Corregidor Bastús y las familias principales se agravó hasta hacer la situación definitiva. Tradicionalmente esta festividad religiosa se iniciaba con varios días de anticipación, convocaba a todos los habitantes en diversas ceremonias, entre ellas a un concurrido y alegre desfile por las calles de la ciudad la noche del 29 de junio. Juan Bastús y Faya prohibió todo tipo de esparcimientos, cuando quiso interrumpir la popular fiesta convocada por la cofradía que nada ahorraba para honrar la solemnidad de San Pedro y el clamoroso séquito de músicos y fieles que se lanzaron a la calle, se generó enorme inconformidad entre los asistentes y enseguida vinieron los reclamos de María Águeda Gallardo. EI déspota funcionario acudió a poner sanción, disolvió sin miramientos el festejo y amenazó groseramente a la señora Gallardo (Pinilla, 1960: pp. 8-22).

La historia oral sostiene que existió una vieja y tirante relación entre el Corregidor Bastús y la familia más distinguida de la 
ciudad: los Gallardo Guerrero; también se cuenta que la matrona de esta familia, María Águeda Gallardo, fue el epicentro de los acontecimientos del 4 de julio de 1810. Aquel gesto altivo de doña Águeda al arrebatar el mando del Corregidor no está confirmado y fue sólo el óleo del pintor pamplonés Marcos Lamus el que escenificó la patriótica intensión.

El desplante del Gobernador Bastús la noche del 29 de junio sirvió para instigar los ánimos en su contra y de excusa para fraguar su violenta destitución. Los irritados pamploneses no esperaron más de cinco días para poner fin a los desmanes del Corregidor, José Gabriel Peña ideó el plan, ejecutado con destreza por Francisco Canal Jácome, Joaquín Villamizar Gallardo, Rafael Emigdio Gallardo Guerrero, Rafael Valencia, Manuel Silvestre y Pedro María Peralta entre otros principales de la ciudad. Planeado el golpe, el 4 de julio en la esquina suroeste del plaza principal "el estimado Joaquín Villamizar" se acercó a Juan Bastús provocándolo decididamente, al pedirle un favor "Joaquinito" fue ásperamente rechazado por el Gobernador, tras su señal corrió la multitud prevenida y apostada para detenerlo. Maniatado lo pasearon por las calles de la ciudad, fue encerrado en el recinto del Cabildo, no le valió pedir auxilio a los Alcaldes Ordinarios ni al clero.

Las fuentes revisadas confirman varios aspectos relacionados con la Independencia de Pamplona. Primero, no hacen referencia al supuesto momento cuando doña Águeda Gallardo arrebató el bastón de mando al Corregidor, tal vez esta escena simboliza en la memoria colectiva de los pamploneses el liderazgo de los Gallardo Guerrero en la conjura contra Juan Bastús, el visto bueno de la matrona de la familia y la preparación de la conspiración en reuniones celebradas en la residencia de los Gallardo. Segundo, ratifican la ideación de un plan por parte de los individuos más distinguidos de la ciudad para deponer por la fuerza al Corregidor. Tercero, corroboran que el representante de la Corona en la Provincia de Pamplona fue destituido, exhibido y encerrado con aprobación de las autoridades del Cabildo, evento que representó una acción radical contra el régimen y que precedió la cadena de acontecimientos revolucionarios en la Nueva Granada. Y cuarto, confirman que desde la noche del 4 de julio de 1810 y en los días siguientes se celebraron juntas populares, pero que a causa del temor y la incertidumbre se postergó la firma del acta hasta finales del mes.

Los motivos que retrasaron la firma del acta que dio cuenta de la formación de la Junta se hicieron explícitos en El Manifiesto de la Junta de Gobierno de Pamplona emitido el 2 de agosto de 1810. La Junta manifestó que la ciudad y su Cabildo se hallaban rodeados por todas partes de inevitables escollos, sitiados por poblaciones hostiles a la causa y poco subordinadas al gobierno de Pamplona.

“La prudencia nos aconsejaba buscásemos la alianza de los Cabildos y lugares de la Provincia, pero la Providencia que (nos) quería probar con este cáliz de amargura (...), nos afligió también con permitir que los Ayuntamientos de las villas de Cúcuta y la ciudad de Girón, se apartasen de la unión de su capital, y se ofreciesen a cumplir gustosos las órdenes de nuestros enemigos".

Además de esta desunión entre los pueblos de la Provincia, la Junta temió también ser acometida al unísono por los Corregidores de Tunja, El Socorro y Maracaibo, tan hostiles como el arrogante Corregidor Bastús. Estas circunstancias y la incertidumbre por no saber lo que ocurría en el resto del Virreinato contuvieron al pueblo de Pamplona y "le impidieron erigir la Junta provisional que apetecía" (Gaceta Histórica, 1960: p.103). 
En el acta del 31 de julio se manifestó que reunidos "Ios individuos del ilustre Cabildo" de Pamplona -que por la deposición del Corregidor Juan Bastús había reasumido la autoridad provincial-, los Prelados de los Conventos, el clero, los jefes y demás oficiales del batallón de milicias recién formado en esta plaza, "se meditó sobre los poderosos motivos que había para la erección de una Junta Provincial" que salvase la patria, ejerciese la autoridad en nombre de don Fernando VII y quedase subordinada al Consejo de Regencia en los términos convenidos por la Confederación general que se establecería en Santafé. Congregado en Cabildo abierto, "el pueblo todo, reasumiendo la autoridad que residía en nuestro legítimo soberano (...), y por su ausencia en el mismo pueblo que se la confió" decidió constituir dicha Junta Provincial (Gaceta Histórica, 1960: pp.102-103).

La Junta de Pamplona requirió la defensa de los tres pilares fundamentales amenazados por el tirano europeo, postura común entre las demás Juntas constituidas. Sus miembros juraron:

“la conservación de nuestra santa religión, obediencia a nuestro legítimo Monarca el Sr. D. Fernando VII, adhesión a la justa causa de toda la nación y absoluta independencia de esta parte de las Américas, de todo yugo extranjero".

Señaló la Junta que en adelante sus miembros debían ser tratados con el título de excelencia y en particular el de Usía, para honrar "Ios dignos ciudadanos que se constituyeron por padres de la Patria". Por último, se ordenó hacer circular el acta por "la América entera" y convidar nuevamente a los Cabildos comprovinciales para que eligiesen sus representantes. El documento registra más de cien firmas, cifra que el indica el compromiso de los pamploneses con la defensa de la patria.

\section{La Junta de la ciudad de San Juan de Girón}

La reforma de 1795 agregó la ciudad de Girón a la recién constituida Provincia de Pamplona, pero desde los acontecimientos políticos que conmocionaron la Nueva Granada durante el segundo semestre de 1810, las autoridades de Girón no se subordinaron a la Junta Suprema constituida para el gobierno de los pueblos de la Provincia. Tras la revolución del año diez, vino la reacción de las ciudades subalternas que intentaron cercenar los vínculos con los corregimientos y sus ciudades capitales, igualándose políticamente al cabildo que funcionaba en la cabecera principal. "Ello obligó a las tres cabeceras de corregimiento (Tunja, Socorro y Pamplona) a emplear la fuerza armada para tratar de mantener vivas las nuevas Provincias-corregimiento, en detrimento de los antiguos derechos de las Provincias subordinadas". Según Armando Martínez, la pugna entre Pamplona y Girón fue el resultado de la defensa de los fueros Provinciales antiguos contra la prolongación de la autoridad de los corregimientos creados en 1795 (Martínez, 1998).

Inicialmente las autoridades de San Juan de Girón se mostraron a favor de la postura que defendió el rompimiento de las lealtades y la reasunción de la soberanía como derecho de todos los pueblos. El 30 de julio el Gobierno de Girón fue depositado en el cura Juan Eloy Valenzuela, párroco de Bucaramanga. La postura "realista" del señor Valenzuela arrastró una percepción similar sobre la actitud de los gironeses durante los primeros meses de la revolución de Independencia. Ahora bien, al examinar el discurso de Valenzuela se evidencian incertidumbres y desasosiegos comunes en el interregno de la crisis monárquica, en varias actas y manifiestos de las juntas constituidas en la Nueva Granada y demás reinos hispanoamericanos se prometió fidelidad al Rey cautivo y se reservó la opinión frente a la Regencia. 
Las vacilaciones del cura Valenzuela fueron producto de un "delirio" y "trastorno de toda justicia y razón" motivado por la acefalia de poder en la recién inventada nación española. En un intervalo de 50 días (junio 9 - julio 30) su discurso político sobre la crisis revolucionaria cambió susceptiblemente. Primero se mostró a favor de la emancipación de los pueblos neogranadinos, aprobó la reasunción de la soberanía conservando los sagrados derechos de la deseada persona del Rey y omitió su postura respecto a la Regencia. Luego apaciguó su ímpetu emancipador, confirmó la decisión de luchar por la defensa de la religión católica y acató la legitimidad del Consejo de Regencia. Durante el lapso transcurrido desde el día que el señor Valenzuela escribió la carta dirigida a José Fernández Madrid hasta la fecha en que se firmó el acta del cabildo extraordinario celebrado en la ciudad de San Juan de Girón, se evidencia un cambio de actitud en el ilustrado cura de Bucaramanga.

Enterado de la caída de España en la península y del contundente progreso del enemigo, preguntó Eloy Valenzuela en los primeros días de junio de 1810: ¿De quién seremos? "Si falta la Madre Patria ¿Cómo quedaremos: emancipados o concertados?" En la respuesta a este interrogante, en carta dirigida a José Fernández Madrid, se descubre la primera postura de Valenzuela frente a la crisis revolucionaria. En ningún caso, adujo, los reinos hispanoamericanos podrían entregarse al asesino francés, esto sería ingratitud y vileza respecto a los sacrificios de "nuestros hermanos" peninsulares. Tampoco podríamos ser de Inglaterra, porque si bien los ingleses tienen riquezas, "son nuestros amigos, son hombres" y no fieras bonapartistas, "se oponen -su- Religión, lengua y carácter". Menos aún podemos ser la heredad de la princesa Carlota Joaquina Teresa de Borbón y Borbón, primogénita del Rey Carlos IV, pues por su matrimonio con Juan VI de Portugal y por las leyes de sucesión, España haría parte de una dinastía extranjera sacada de una Provincia que fue suya y se reveló en tiempos del débil Felipe IV (Martínez, 2006: pp. 279-286).

¿De quién seremos? Seremos emancipados o concertados, en palabras de Eloy Valenzuela, no podríamos ser lo segundo porque esto implicaría vileza, traición, subyugación, vasallaje y desconocimiento de nuestro genio y cultura. Así las cosas, sólo podríamos ser de nosotros, adueñarnos de nuestro destino como Estado nación; dadas las circunstancias tras el súbito desplome de la Monarquía española, no quedó otra opción que reasumir temporalmente la soberanía y conservarla hasta el regreso de los ansiados reyes. Hasta aquí queda claro entonces la postura inicial del señor Valenzuela en vísperas de la Independencia, siendo un presbítero de régimen duro y conservador, compungido por el estado de las cosas, no vaciló para declararse a favor de la emancipación quitándole sin embargo el rótulo de revolución. Sus palabras testifican este primer talante:

"Nuestra emancipación no es deslealtad, no es novelería, es obra del cielo, y Dios quiera que el egoísmo y la relajación no la desquicien de sus fines. Viene a ser como un hijo obediente a quien faltan sus padres. No es un proyecto de insurrección o trastorno (...). Nadie será obedecido sin que la voluntad nacional señale primero su empleo y la parte de mando que se le confía. Por tanto, lejos de temer debemos solicitar la concurrencia, reunión, y consentimiento de los votos en estas o las más eficaces ideas, a fin de evitar la anarquía del Reino o su usurpación [...). Basta que respetemos a los sagrados derechos inherentes a la deseada persona de Fernando, en lo demás no debe haber más ley que la salud del estado [...]. Este poder no nos ha venido por inconstancia, mucho menos 
por infidelidad o desafecto: ha sido una crisis que no merece el nombre sospechoso de revolución, es más bien la expresión sincera de aquel infinito que mueve aún a los brutos para defenderse: en una palabra ha sido obra del cielo, recompensa digna del largo sufrimiento a una administración inepta, caprichosa y corrompida (...). Concluyamos pues que debemos ser nuestros reuniéndonos en un estado que sin abrazar demasiada extensión nos proporcione ventajas para el fomento interior y para las relaciones exteriores" (Martínez, 2006: p. 279-286).

Es innegable que estos fragmentos parecen el repertorio del más eximio y moderno prócer independentista, en él se habla de emancipación, voluntad nacional, del consentimiento a través de los votos y del deber de ser nuestros reuniéndonos en un Estado -nacional-. Sin embargo, este frenesí liberal menguó en los pensamientos y acciones del señor Valenzuela al tiempo que otros líderes y junteros neogranadinos abrazaron con vehemencia la causa revolucionaria. Su postura monarquista expresada en el cabildo extraordinario celebrado en Girón el 30 de julio de 1810 era de esperarse, puesto que desde joven Valenzuela cultivó lealtad hacia la Monarquía española, su estampa se consideró como el baluarte más fuerte de la religión y en 1809 juró públicamente fidelidad a don Fernando VII.

El acta del cabildo extraordinario que depositó el gobierno de Girón en el Señor Juan Eloy Valenzuela es un documento que por su particularidad merece ser revisado. Comparada con otros documentos que testificaron la formación de juntas de gobierno autónomas sobre el principio de la reasunción de la soberanía, el acta del 30 julio pareció más una jura de fidelidad y una colección de recomendaciones para el buen gobierno y prosperidad de la recién establecida "Provincia de Girón". Varios puntos Ilaman la atención en este documento redactado seguramente por el ilustrado criollo depositario del gobierno de Girón. El encabezado del acta justificó las circunstancias que llevaron al pueblo de Girón convocado en su plaza mayor a conferir el mando en su hijo más notable. Enterados de las noticias en ambos lados del atlántico, del feroz avance de las tropas francesas en la península española y del movimiento revolucionario en Hispanoamérica, sólo quedó la opción del autogobierno. Así fue como se referenció el hecho:

“Impuestos todos de los acontecimientos políticos que en nuestra nación han restituido al Pueblo en el goce de sus derechos, dijeron de común acuerdo -el Cabildo y el vecindario- , en altas e inteligibles voces, que depositaban el gobierno de la Provincia en el Dr. Don Eloy Valenzuela" (Martínez, 2006: pp. 286-289).

Asumido el mando, Valenzuela procedió con el nombramiento de dos "vocales" -los Alcaldes ordinarios- y un secretario -su hermano-, esto supuso algo así como la formación de una junta de gobierno en la que el líder fue su capellán. Valenzuela señaló que no gustaba de los que cuentan con los pueblos e individuos sólo para establecer su mando y luego los excluyen en lo que toca a la opinión y los beneficios. En adelante, Valenzuela habló en nombre de la Provincia "para atender su tranquilidad y beneficio común", una nueva entidad que desconoció la autoridad de Pamplona como ciudad capital, se igualó a su status político y procedió con el supuesto consentimiento de las parroquias de su jurisdicción. Según quedó en el acta, Valenzuela consiguió el aplauso del vecindario tras manifestar sus instrucciones para el buen gobierno de la Provincia.

El acta que testifica la reunión de los gironeses en "cabildo pleno" contiene las extensas preguntas de la jura propalada por el señor Valenzuela para “explorar el 
consentimiento de la Provincia sobre los puntos sustanciales que habían de servir de base al nuevo pacto". Cada uno de estos interrogantes permite precisar la postura del gobierno de Girón y el rumbo que tomaría. En un ambiente de tenaz religiosidad empezó la jura abordando el tema de mayor centralidad, la Fidelidad hacia el Rey y la restitución del poder soberano en caso de recuperar su trono:

“¿Juran ustedes la monarquía hereditaria de Fernando Séptimo (que Dios guarde), si la Providencia lo restituye al trono de las Españas, pero con las mitigaciones, cautelas y reformas que se anunciaron desde los principios, y cuya necesidad se ha hecho cada día más patente?"

Las anteriores líneas fueron quizás las que más asentaron la actitud realista del señor Valenzuela y del gobierno que presidió. Sin embargo, en caso de ser restituida, Valenzuela exigió fidelidad pero a una monarquía contrapesada por los principios de la modernidad política, si se quiere, un espectro de monarquía constitucional.

Jurada la fidelidad hacia Fernando VII, fue preciso hacer lo mismo en cuanto a la unión de las Provincias neogranadinas, la defensa de la recién constituida Provincia de Girón y del gobierno instaurado para su conducción. Valenzuela exigió el juramento de unión y amistad con las "Provincias comarcanas" que quisieron hacer parte de la confederación neogranadina y sostener la independencia, la unión federativa fue el modelo de gobierno general que concibió. No obstante, sospechó que las buenas relaciones entre Provincias no se darían fácilmente, pues Girón se constituía como Provincia al desconocer y usurpar la soberanía provincial de Pamplona. Como presagiaba la reacción militar de los pamploneses o de algunas parroquias inconformes, Valenzuela hizo jurar a sus paisanos la defensa "a todo trance - de- la libertad de esta Provincia contra cualquiera otra que nos quiera subyugar, predominar o poner en contribución; y prestar auxilio a las que en igual lance invoquen nuestra ayuda".

Luego reclamó obediencia y sumisión al gobierno que por aclamación se acababa de establecer. Aceptados todos los puntos por las gentes del vecindario, repuso: "si alguno hiciere o aconsejare en contrario, que venga sobre él la maldición de Dios y la execración de los hombres. Amén" (Martínez, 2006: pp. 286-289).

Hasta aquí vale subrayar cuatro conclusiones obtenidas tras la revisión del acta de Girón: la postura realista del Señor Valenzuela fue un hecho, pero en este documento se refirió a una monarquía moderada por los principios de la época. El acato al Consejo de Regencia que algunos historiadores achacan al señor Valenzuela y que afirman dejó testimonio en el acta del 30 de julio es un desacierto, pues el documento no hizo referencia a la legitimidad de este cuerpo. La formación de la Provincia de Girón y de su respectivo gobierno, soberano y autónomo, sirvió para declarar implícitamente la independencia de Girón respecto al dominio de la Pamplona. Finalmente, el acta plasmó con claridad la decisión de luchar por la defensa de Dios, del Rey y la Patria, pero por su estilo no deja de ser un acta atípica en la que se nota más la pluma de un hombre de la iglesia que de leyes.

Las pretensiones de Girón de formar su propia Junta de Gobierno y establecerse como una provincia independiente fueron controladas rápidamente por las autoridades de Pamplona a través del instrumento de la fuerza. Las hostilidades entre estas ciudades se aplacaron a finales de la primera mitad de 1811, cuando la Junta Superior Gubernativa de la Provincia de Pamplona ofreció olvidar las incursiones armadas adelantadas por los gironeses entre los meses de octubre y diciembre 
del año anterior. Esta pugna fue el resultado de la independencia proclamaba por Girón sobre la cabecera provincial y de la defensa de antiguos fueros contra la prolongación de la autoridad del corregimiento creado a finales del siglo XVIII. Si bien persistió la amenaza separatista dada la estrategia anexionista del Estado de Cundinamarca que ofreció a los pueblos secundarios ayuda militar y una mejor representación política en los cuerpos de la nación, el presidente de la Junta de Pamplona convocó a los gironeses a la unión Provincial en estos términos:

“Gironeses: el gobierno -de Pamplona- os recibe con la dignidad que corresponde, y con la distinción que os merecéis. Se acabaron las divisiones pasadas, sois pues pamploneses: Componéis parte de esta gran familia, y una parte preciosa. Apresuraos por enviar vuestro representante: el gobierno olvida absolutamente que habéis sido en otro tiempo causa de su disgusto y pesar; sólo se acuerda que sois sus hijos, y unos hijos dignos de toda su compasión, y que vais ya a merecer su beneficencia (...)"6.

\section{La Junta de la ciudad de Ocaña}

Durante el periodo indiano Ocaña perteneció a la antigua Provincia de Santa Marta, por esta razón la historia de su Independencia se relaciona con la de su capital provincial. La ciudad Santa Marta conformó su Junta de Gobierno el 10 de agosto de 1810, sus ciudadanos motivados por los sucesos de Santafé y Cartagena, reclamaron al Gobernador José Víctor Salcedo de Villa su formación. Una vez constituida, la Junta quedó bajo las órdenes de Salcedo, su nombramiento como Presidente le permitió continuar en el ejercicio de las funciones administrativas y militares. La mayoría realista en

6 La Junta de Pamplona al pueblo de Girón. Pamplona, 13 de mayo de 1811. En: Semanario ministerial del gobierno de la capital de Santafé en el Nuevo Reyno de Granada, no. 19 (20 de junio de 1811), pp. 85. AR, vol. 8, f. 77. el recién creado cuerpo político defendió el régimen colonial y la religión católica. La escasez de ilustrados, la pasividad del clero local y el predominio de comerciantes y burócratas, explica el carácter realista de la Junta de Santa Marta.

La actitud reaccionaria de la Junta de Santa Marta y de su Presidente, pronto se descubrió para contener los ánimos que apuntaron al autogobierno y la reasunción de la soberanía de los pueblos. Motivado por la reacción realista del pueblo de la Ciénaga, apoyado por algunos monarquistas socarrones y tras instar ayuda a Cuba y Panamá, el Presidente Salcedo se movió para oponerse al avance patriota. En corta asonada contra los escasos rebeldes de la Provincia, los patriotas fueron reducidos y dispersados por completo. Finalmente, el Consejo de Regencia designó a Tomás Acosta Gobernador de la Provincia, quien acabó con la débil Junta, convirtiéndose de esta manera Santa Marta en el bastión realista al que acudieron los enemigos de la Independencia. En diciembre 1811 se formó otra Junta en la ciudad de Santa Marta, influenciada en sus criterios por realistas emigrados de Cartagena, este cuerpo político tuvo menor participación de la élite local y muy poca trascendencia.

Por su parte, la ciudad de Cartagena declaró su Independencia total de España el 11 de noviembre de 1811, entre su primer patriótico plan estuvo la decisión de invadir la Provincia de Santa Marta, arrebatar el dominio a los realistas y establecer un gobierno republicano. Manuel Rodríguez Torices, líder de la Independencia en Cartagena, colocó bajo las órdenes del francés Pierre Labatut las tropas de su Provincia, para dirigir la marcha contra Santa Marta. En el segundo semestre del año doce, arribaron a Cartagena los oficiales Cortés, Carabaño, Labatut y Bolívar, quienes emprendieron la campaña por los pueblos del bajo Magdalena, dominados por las fuerzas realistas. Los patriotas 
arrasaron con el enemigo en los pueblos de Sitio Nuevo, Guaimaro, Pueblo Viejo, El Piñón, Pedraza, San Antonio, Tenerife, Morro, Pinto, El Banco, Buenavista, Guamal, San Juan, San Fernando, Tamalameque y Chiriguaná. Después de controlar la parte baja del Río de la Magdalena, el coronel Bolívar recibió permiso de Cartagena para marchar hasta la Ciudad de Ocaña, donde llegó en los primeros días del año 1813. Entre tanto, el 6 de enero del mismo año entró triunfante a Santa Marta el coronel Pierre Labatut al servicio del gobierno de Cartagena.

Después de repasar la situación general en la Provincia de Santa Marta entre los años 1810-1813, es sugerente revisar la experiencia juntera de la Ciudad Ocaña, poco conocida por la historia nacional e importante para comprender las dinámicas locales del proceso de Independencia. Alejo Amaya relató en el texto Los Genitores, que de Santa Marta y Cartagena llegaban a la ciudad de Ocaña confusos rumores de lo que sucedía en España. Como en toda la Nueva Granada, "reinaba en la ciudad una zozobra grandísima cuando cayó como una bomba la noticia de los sucesos de Bayona". Enterados de las noticias que de Europa trajo el capitán Sanllorente a Santafé y al resto de la Nueva Granada, entre ellas la formación de una Junta de notables en Sevilla que gobernaba en nombre del augusto prisionero, los ocañeros cumplieron lo ordenado por dicha Junta y por el gobierno de Santa Marta para el "reconvencimiento" de Fernando VII. Sin postergar la acción, en noviembre de 1808 el pueblo de Ocaña juró y proclamó fidelidad al Rey, cumpliendo con los grandes festejos y ceremonias acostumbradas. Sin embargo, luego vino el descontento en todas las partes del reino, los intransigentes procederes de los servidores de la Corona y el desconocimiento de la igualdad de Hispanoamérica como "parte integrante de la nación" española, hizo estallar un movimiento revolucionario al que Ocaña entró de lleno (Amaya, 1950: p. 208-211).

Las noticias de lo sucedido en Pamplona y EI Socorro fueron conocidas en la ciudad de Ocaña a través de Antonio Quintero Copete, joven principal que estudiaba en Pamplona y presenció la violenta deposición del Corregidor Juan Bastús; Quintero se propuso despertar la simpatía por la causa independentista entre los vecinos de la ciudad, tarea que se le facilitó después de conocerse a través de un correísta lo acontecido en Santafé el 20 de julio. Informado el Cabildo de la situación en otras ciudades del reino, determinó arreglar las instrucciones que llevaría su representante a la Junta creada el 10 de agosto en Santa Marta. Las noticias de Quintero Copete motivaron al grupo republicano de Ocaña liderado por Miguel Ibáñez Vidal y el padre Alejo María Buceta. Aceptada la invitación a formar Juntas patrióticas, se reunieron el 20 de octubre de 1810 los miembros del cabildo, Justicia y Regimiento de Ocaña, para perfeccionar sus instrucciones al gobierno provincial, "pero no con -el- ánimo decidió de emanciparse de la medre patria, sino con el único y firme propósito de hacer valer sus derechos como parte integrante de la Provincia de Santa Marta" (Pacheco, 1983: pp. 75-81).

Las instrucciones elaboradas por el Síndico Procurador Francisco Solano Jácome fueron revisadas y aprobadas por los miembros del Cabildo local: Manuel Antonio de Lemus y Ramón de Trillos, Alcaldes ordinarios, el Alférez Real Antonio Luis Jácome, los Regidores capitulares Francisco Navarro, Cayetano Antonio Villareal, Francisco Quintero Príncipe y el Escribano público y real Francisco Gómez Castro. A estas instrucciones se ciñó Francisco Aquilino Jácome, comisionado por el cabildo de Ocaña a la Junta de Santa Marta. Este representante de los ocañeros no pudo asistir a la capital de su Provincia a imponer sus puntos de vista, debido a las 
acciones del Gobernador Tomás Acosta que con su batallón de voluntarios fieles a Fernando VII, disolvió violentamente la Junta de Santa Marta y convirtió la ciudad en un fortín realista.

La presencia en Ocaña a finales de 1810 de José Víctor de Salcedo, Teniente Capitán de la primera compañía del regimiento Fijo de Santa Marta, frustró la consolidación de la Junta de Gobierno de Ocaña. Los sucesos de Santa Marta y la reacción de los realistas en la Provincia motivaron la desunión y disparidad de criterios entre los dirigentes ocañeros. Fue así como en la ciudad se enfrentaron dos bandos, el de los patriotas defensores de una Nueva Granada libre y con vida política propia, contra el de los regentistas, partidarios del gobierno de las Cortes en nombre de Fernando VII. El movimiento independentista duró en Ocaña hasta la llegada de la expedición realista al mando del Teniente Coronel Ignacio de la Rus, la dispersión y el exilio fue la única opción de los líderes patriotas.

Si bien el comisionado Francisco Aquilino Jácome no logró pronunciar las instrucciones del Cabildo de Ocaña ante la Junta de Santa Marta, depuesta por Tomás Acosta, es ilustrativo revisar este histórico documento para entender el carácter y parecer de las autoridades ocañeras durante 1810. Un primer punto que merece destacarse hizo alusión al primitivo derecho al autogobierno de los pueblos en caso de una vacante regia, insinúa de alguna forma la independencia de Ocaña respecto a la capital provincial. En este caso, su manifiesto deseo de reasumir la soberanía y el recelo de las autoridades ocañeras frente a la Junta de Santa Marta, estuvo justificado por las sobradas sospechas que denunciaron la postura realista de los samarios. A esto se añade que la opinión de los capitulares de Ocaña estuvo de acuerdo con la formación de un cuerpo político nacional en el que estuviesen representados todas las Pro- vincias neogranadinas y los pueblos que las conformaron. El siguiente fragmento de las referidas instrucciones confirma este parecer:

“Esta ciudad, tan leal a su rey, como adicta a sostener su libertad y la causa común, derramará la sangre de sus moradores por defender tan sagrados objetos; prestará cuantos auxilios pueda para asegurar la unión con las Provincias, con las que se congratula por la feliz revolución de nuestras opiniones políticas; conoce hallarse restituida a sus primitivos derechos; ve la necesidad de afianzarlos y contribuye por medio de su representante al fin propuesto por la Capital del Nuevo Reyno de Granada y Santa Marta para establecer un nuevo Gobierno que haga floreciente a la América (...)" (Amaya, 1950: p. 212).

La representación del Cabildo de Ocaña fue contundente al subrayar su autonomía frente la Junta de Santa Marta, a la cual reconoció sólo para cooperar con la causa común, es decir, con el proyecto de las Provincias unidas de la Nueva Granada. Asimismo, las autoridades ocañeras increparon con fuerza la ilegitimidad de la Junta Superior Provincial y la usurpación de sus derechos por este improbado cuerpo, al argumentar la desigualdad entre el grueso número de representantes por la ciudad de Santa Marta y los demás sitios de la Provincia. En lo sucesivo las instrucciones del Cabildo de Ocaña se extendieron en recomendaciones para mejorar el gobierno, la administración, las rentas y el comercio en la Provincia, en el marco de unas reformas liberales. Las instrucciones del Cabildo de Ocaña buscaron el reconocimiento de cierta autonomía respecto al gobierno de Santa Marta, subordinándose sin embargo a la Suprema Junta Provincial para mantener la unión de los pueblos y las Provincias neogranadinas. Esta es la razón que explica por qué los ocañeros no crearon su 
propia junta de gobierno con la respectiva acta que lo constatara y prefirieron en cambio obedecer a una Junta que pronto mostró su fidelidad al yugo español, como fue el caso de Santa Marta.

La "contrarrevolución" de Tomás Acosta, Gobernador de la Provincia, dejó a los ocañeros sometidos a un duro régimen despótico ejercido en nombre de los poderes de España. Los partidarios de la Independencia fueron perseguidos y forzados a exiliarse en el resto de la Nueva Granada. La suerte y los planes de muchos de los notables ocañeros que lideraron la Independencia de su ciudad, confirman su convicción respecto al tema de la libertad y el derecho al autogobierno de los pueblos. Más aún cuando hubo constancia de la tenacidad de las represalias y persecuciones a las que fueron sometidos por el gobierno de Santa Marta. Sin temer la envestida realista, los exiliados intentaron organizar un movimiento patriota para liberar su ciudad, al tiempo que los regentistas ocañeros y las autoridades de Santa Marta no dieron tregua en el acecho y espionaje de tales líderes. Entre estas acciones, se destacó la orden el Alcalde de Ocaña de enviar un espía "de toda satisfacción y confianza a los lugares del reino con el objeto de indagar e inculcar el estado y situación en que se hallan los sujetos que emigraron de esta, sus movimientos, armamentos, tropas y disposiciones que tengan para invadir a este puerto.

Nada pudieron hacer estos exilados ocañeros para invadir y recuperar el control de su ciudad. Pero el año 1813 trajo un efímero destello de libertad y victoria, pues por el bajo Magdalena descendía Labatut y Bolívar liberando los pueblos de la Provincia de Santa Marta, la ciudad de Ocaña y luego las principales localidades de la Provincia de Pamplona. La llegada de Bolívar a Puerto Nacional fue motivo suficiente para que se desplomara la administración realista de Ocaña. Cuando la comisión enviada por las autoridades de Ocaña para entenderse con Bolívar, escucharon de su propia voz que continuaría la marcha hasta esta ciudad, se apresuraron a establecer una Junta patriótica y preparar el recibimiento de la tropa libertadora. Bolívar arribó a la ciudad escoltado por sus oficiales y la tropa, intercambió los saludos correspondientes con las autoridades locales, el entusiasmo del pueblo durante el desfile fue grande, acompañado por la música de la banda militar, por las flores arrojadas desde las casas y los arcos que adornaron las calles (Páez, 1972: pp. 20-25).

La presencia de Bolívar y la liberación de los pueblos de la Provincia de Santa Marta motivaron la formación de la Junta de Ocaña y la firma el acta de Independencia el 7 de abril de 1813. Este documento desconoció el régimen español, reconoció el poder que emanó de Simón Bolívar y la revolución que él acaudillaba, juró sostenerla y no ahorrar sacrificio para lograr la emancipación de España. Aquel día la muchedumbre reunida en la plaza destrozó los sellos de España y los escudos de armas de los Oficiales, depuso a los regidores realistas y nombró a los miembros de la Junta de Gobierno: Sebastián Llain y Sarabia, Juan Pérez, Bernardo Barbosa y Miguel Martínez Troncoso. Este cuerpo levantó el acta la cual fue firmada por los principales de la ciudad, entre ellos los exiliados que buscaron liberar su comarca (Pacheco, 1983: pp. 78-81). Algunos historiadores locales afirman que el 9 de abril de 1813 los señores José Manuel Ibáñez, Bernardo Pacheco y Gabriel Quintero formaron una nueva Junta por instrucción de Bolívar (Páez, 1972: p. 30). La proclama del Coronel Bolívar en enero 12 de 1813 cerró esta parte de la historia de la Independencia de Ocaña y la formación de su Junta:

“(...) Todo prueba que los tiranos han sido destruidos, que su reino ha cesado para siempre y que os halláis 
libres de sus depredaciones y ultrajes (...). Sed, habitantes de Ocaña, dignos de llamaros ciudadanos de la Nueva Granada; iguales a vuestros hermanos en virtud política, labor militar y costumbres republicanas para que os hagáis acreedores a la honras que les habéis merecido elevándoos al alto rango que ellos ocupan en el teatro del mundo (...)".

\section{Reflexiones finales}

El estudio de la formación de juntas locales en el nororiente del Virreinato de la Nueva Granada permitió subrayar las siguientes conclusiones que tienen un carácter reflexivo y no la pretensión de un juicio histórico irreductible. Le primera reflexión final nos remite a la justificación del periodo comprendido por la investigación, 1810-1816. Esta época de cambio que en la memoria histórica de la nación debe alojarse con el nombre de la Primera República de la Nueva Granada independiente, sirvió para ajustar las fechas extremas del proyecto investigativo. Sin desconocer los aportes que las Provincias del nororiente realizaron a la Independencia nacional después del año 1816, es innegable que sus más grandes esfuerzos y contribuciones para esta causa fueron realizadas en los tiempos de la Primera República, lideraron primero el proceso de formación de Juntas de Gobierno neogranadinas y luego resistiendo el embate de las fuerzas realistas que marcharon con superioridad desde la frontera venezolana entre los años 1812-1816.

La segunda reflexión apunta a la interpretación que puede hacerse a las llamadas Independencias neogranadinas y al calificativo que desde la ciencia histórica recibe este acontecimiento. Si se logrará hacer un ejercicio a través del cual se pudiese interpretar el acontecer en su mismo contexto histórico, y no desde el tiempo presente ni desde sus referentes teórico-conceptuales incompatibles por su anacronismo, la Independencia representaría un proceso revolucionario. El propósito no estuvo en debatir desde la teoría social sí la Independencia fue una revolución completa, inconclusa o truncada; es más objetivo y justo leer los acontecimientos en su tiempo, pues al pensar la Independencia en su época, los hechos son en absoluto revolucionarios. En la mentalidad, representaciones y temores de los actores y líderes del proceso la Independencia se leyó como una peligrosa acción revolucionaria contra un régimen tan antiguo y despótico como el de la Monarquía española, al que se resistió política y militarmente. A doscientos años de aquellos acontecimientos, algunos historiadores concluyen que los reinos hispanoamericanos experimentaron desde 1810 un doble proceso que configuró el delito de lesa majestad: una Independencia que transfirió la soberanía a los pueblos y una Revolución que intentó acercarlos a la modernidad política.

La tercera reflexión concluyente parte de lo que podría llamarse un descontrol de este doble proceso, reflejado en el debate sobre las soberanías provinciales. La explosiva reasunción de la soberanía de los pueblos neogranadinos terminó en una incontable colección de declaraciones de Independencia donde la Monarquía, la Regencia o las Cortes no fueron los únicos referentes. Las pugnas heredadas del régimen indiano y la insubordinación respecto a las cabeceras jurisdiccionales enfrentaron a pueblos y Provincias en disputas por pequeñas y privadas independencias. De esta manera, la revolución que representó la segunda parte de este proceso de cambio y que buscó practicar en la Nueva Granada los principios liberales de la modernidad política, resultó ajena a los valores heredados del mundo indiano. Por esta razón, se sacrificaron importantes premisas de la modernidad como la unidad nacional o la idea de una república unitaria que sólo así resistiría al enemigo español. Pero estos reveses en 
la construcción del Estado nación no son suficientes para descalificar la experiencia inicial con nombres peyorativos, es más acertado nombrar a este periodo como la Primera República.

Esta "explosión de soberanías" o "eclosión del movimiento juntero" neogranadino que sobrevino a la crisis de la Monarquía española, abre la reflexión sobre un cuarto aspecto definitivo en la presente investigación. Las nuevas lecturas sobre la Independencia resaltan el significado de las experiencias locales que la hicieron posible. En contra del marcado centralismo político plasmado hasta ahora en la historia nacional, un grupo de historiadores de provincia logró demostrar que el proceso revolucionario del que se habló dos párrafos arriba empezó en la periferia neogranadina. El adormecimiento de Santafé respecto a la crisis monárquica hizo que los primeros movimientos por la Independencia surgieran en algunas Provincias y que el poder político de la capital virreinal se redujera al tiempo que las localidades ganaron autonomía. La conmemoración histórica del Bicentenario de la Independencia permitió en definitiva la descentralización de sus miradas y la resignificación de las experiencias locales y del papel de sus actores.

Las historias locales de las Independencias neogranadinas resaltan el protagonismo de las élites y es sobre este aspecto que se extiende la última reflexión. En el proceso revolucionario experimentado con desorden por los pueblos del suprimido Virreinato, el liderazgo político, ideológico y militar de un grupo de individuos que se definió como de notables o principales y que se configuró a la sombra del régimen indiano monopolizando el poder y todo tipo de recursos, fue la pieza central para echar a andar el movimiento. Aquel liderazgo de las élites locales se concretó en tres aspectos: primero, la formación de Juntas de Gobierno que auspiciaron el tumulto y la deposición violenta de las autoridades peninsulares, preparando las arengas, actas, manifiestos y demás documentos que argumentaron la reasunción de la soberanía; segundo, en la reorganización de los cuerpos políticos que asumieron las funciones de gobierno, en la normalización y legitimización del nuevo régimen independiente a partir de la elección de representantes, conformación de Colegios Electorales y proclamación de constituciones provinciales. Tercero, en el direccionamiento de la guerra contra las fuerzas realistas que con base en un pleno convencimiento de la causa motivaron la conscripción de otros sectores sociales y apertrecharon los ejércitos patriotas sacrificando hasta sus patrimonios.

\section{Referencias}

AMAYA, A. (1950). Los Genitores (2 ${ }^{\mathrm{a}}$ ed.). Bogotá: Antares.

GACETA HISTÓRICA. (1953). Órgano oficial de la Academia de Historia de Norte de Santander, 15.

GACETA HISTÓRICA. (1960). Órgano oficial de la Academia de Historia de Norte de Santander. 49-50,

GUERRA, F.X. (1998). De la política antigua a la política moderna: La revolución de la soberanía. En: Guerra, F.X. y Lempérière, A. Los espacios públicos en lberoamérica: Ambigüedades y problemas. Siglos XVIII-XIX. México: Fondo de Cultura Económica.

HAMNETT, B. (1985). La política española en una época revolucionaria 1790-1820. México: Fondo de Cultura Económica.

MARTÍNEZ, A. (1998). El legado de la patria boba. Bucaramanga: Sistemas y Computadores.

MARTÍNEZ, A (Ed.), (2006). Juan Eloy Valenzuela y Mantilla, Escritos 1786-1834. Bucaramanga: Universidad Industrial de Santander.

MARTÍNEZ, A. \& Quintero, I. (2008) Actas de formación de juntas y declaraciones de independencia (1809-1822): Reales Audiencias de Quito, Caracas y Santafé. Bucaramanga: Universidad Industrial de Santander.

MARTíNEZ, A. (2010). La Independencia en Pamplona y El Socorro. En Revista Santander segunda época, 5.

OCAMPO, L.J. (1999). El proceso ideológico de la emancipación en Colombia. Bogotá: Planeta.

QUIJADA, M. (2003). ¿Qué nación? Dinámicas y dicotomías de la nación en el imaginario hispanoamericano. En Annino, A. \& Guerra, FX. Inventando la Nación. Iberoamérica siglo XIX. México: Fondo de Cultura Económica.

PÁEZ, J. (1972). Noticias históricas de la ciudad y provincia de Ocaña. Ocaña: Publicaciones de la Escuela de Bellas Artes.

PACHECO, R. (1983). Movimiento de Independencia de Ocaña. En Gaceta Histórica. Órgano oficial de la Academia de Historia de Norte de Santander, 94.

PINILLA, A.M. (1960). El grito de independencia de Pamplona. En Gaceta Histórica. Órgano oficial de la Academia de Historia de Norte de Santander 
49-50.

RODRÍGUEZ, J.E. (1998). La Independencia de la América Española. México: Fondo de Cultura Económica - Colegio de México.

RODRÍGUEZ, J.E. (2004). La Revolución de la Independencia Hispanoamericana frente a las Revoluciones Atlánticas. En Martínez, A.

\& Bustos, G. La Independencia en los Países Andinos: nuevas perspectivas. Bucaramanga: Universidad Industrial de Santander. 